International Journal of Research in Nursing 1 (1): 1-7, 2010

ISSN 1949-0194

(C) 2010 Science Publications

\title{
Cardiovascular Disease Risk Factors among Adult Australian-Lebanese in Melbourne
}

\author{
Lina Shahwan-Akl \\ School of Health Sciences, Royal Melbourne Institute of Technology University, \\ Discipline of Nursing and Midwifery, Bundoora, Victoria, Australia, 3083
}

\begin{abstract}
This descriptive exploratory study reports on the prevalence of Cardiovascular Disease (CVD) risk factors among adult Australian-Lebanese migrants living in Melbourne. This study fills a gap in extant research regarding CVD risk factors within this ethnic community in Melbourne. Problem statement: Australia's multicultural society consists of more than 200 ethnic groups and nearly a quarter of the Australian population are born overseas. Thus, the health status of immigrants significantly affects the national health profile. Whilst the prevalence of CVD risk factors has been researched in several ethnic communities in Melbourne, it has never been studied among the Australian-Lebanese migrants living in Melbourne. Approach: A convenience sample of 200 adult Australian-Lebanese men (88) and women (112) residing permanently in Melbourne completed a structured questionnaire based on the 1989 National Heart Foundation Risk Factor Prevalence Study (NHFRFPS, 1990). Physical measurements of height, weight, Body Mass Index (BMI), waist and hip circumferences, blood pressure and reported cholesterol levels were also obtained. Results: Subjects were aged between 20-69 years and manifested many risk factors for CVD. Lack of physical activity and increased weight were prevalent across all age groups. Hypertension increased with age and smoking was more prevalent among the Australian-Lebanese when compared with the general Australian population. Multivariate forward logistic regression analysis found that the strongest predictors of CVD risk factors were age, gender, level of education and length of residence in Australia. The most vulnerable were older men with a lower level of education who had resided in Australia for more than 10 years. Conclusion: The CVD risk factors among the Australian-Lebanese included overweight and obesity, lack of physical activity and high levels of smoking. The findings warrant further research among other Arabic speaking groups who have similar social and cultural practices. The findings demonstrate the need for culturally tailored health promotion programs aimed at reducing CVD risk behaviors among this ethnic group.
\end{abstract}

Key words: Cardiovascular disease, risk factors, Lebanese immigrants, ethno-specific health promotion

\section{INTRODUCTION}

Despite its decline over the past 40 years, Cardiovascular Disease (CVD) remains the leading cause of morbidity and mortality in Australia, accounting for $34 \%$ of male and $39 \%$ of female deaths (Al-Roomi et al., 1989; Australian Institute of Health and Welfare, 2004; Australian Bureau of Statistics, 2006; 2007). This paper reports on a study which investigated the prevalence of CVD risk factors among adult Australian-Lebanese living in Melbourne, Australia.

Background: The national health profile is significantly affected by the health of the immigrants. It has been well documented that newly arrived immigrants have a lower mortality rate from Coronary Heart Disease (CHD) than Australian-born people (Biddle et al., 2007). This disparity is explained, in part, by the stringent selection processes of migration approval whereby only healthy immigrants are selected (Richardson et al., 2004; AIHW, 2002; Department of Immigration and Multicultural and Indigenous Affairs, 2002; 2003). However, it has been noted that the incidence of CHD among migrants rises with increased duration of residence in Australia (Australian Institute of Health and Welfare, 1992; Department of Immigration and Citizenship, 2008). This pattern has been partially attributed to the stress of migration and settlement, socio-economic disadvantages experienced by many early migrants, loss of social status, changes in lifestyle and limited access to health information (AIHW, 2002; Minas, 1996).

In the 1980s three national studies were conducted in Australia into the prevalence of CVD (National Heart Foundation of Australia, 1982; 1985; 1990). Other CVD risk factor studies were conducted on specific 
ethnic populations, including Greeks (Wilson et al., 1993) Italians (Ireland and Giles, 1996), Chinese (HsuHage and Walqvist, 1993) and Vietnamese (Rissel and Russell, 1993). However, no studies targeted the Lebanese, who began migrating to Australia in the 1850s and now constitute one of the largest Arabicspeaking ethnic communities. This study provides an overview of the CVD risk factor profile of a sample of adult Australian-Lebanese living in Melbourne.

\section{MATERIALS AND METHODS}

This was a descriptive explorative study with a cross-sectional design. Ethics approval was obtained from the Human Research Ethics Committee (HREC), RMIT University, Bundoora, Australia. The conduct of the study and the management of the data conformed to the University's HREC requirements.

Sample: A non-random snowball sampling strategy was employed to recruit people living in geographic areas in Melbourne with a high concentration of Australian-Lebanese (Australian Bureau of Statistics, 2006). This sampling strategy is commonly used in studies of ethnic communities (Ecob and Williams, 1991; Chaturvedi and McKeigue, 1994 Plunkett and Quine, 1996; Brown et al., 1997; Small et al., 1999). Lebanese community leaders, religious leaders and community members assisted in the provision of contact names and telephone numbers of Australian-Lebanese households. In addition, to familiarize the community with this study and to encourage recruitment of subjects, the study was advertised twice over a two week period on the SBS Arabic radio program in Melbourne. A sample of 200 adult Australian-Lebanese (88 men and 112 women) was obtained (Table 1). Written informed consent was obtained from all subjects prior to commencement of the study. All subjects were reassured about the anonymity and confidentiality of the data. Subjects were required to complete a questionnaire and participate in health assessment measurements.

Questionnaire: Risk factor data: Risk factor data were obtained via a questionnaire based on the 1989 National Heart Foundation Risk Factor Prevalence Study (National Heart Foundation of Australia, 1990). The questionnaire took around15-20 min to complete and elicited socio-demographic characteristics, dietary habits, lifestyle behaviors (including smoking and exercise), medical history, past medical conditions (including angina, heart disease, heart attack, stroke, diabetes, self-reported cholesterol levels) and types of treatment, if any, for these conditions.
Table 1: Sociodemographic characteristics of Australian-Lebanese subjects $(\mathrm{N}=200)$

\begin{tabular}{|c|c|c|c|c|}
\hline & Men $\mathrm{n}=88$ & Percent & Women $\mathrm{n}=112$ & Percent \\
\hline \multicolumn{5}{|l|}{ Age in years } \\
\hline $20-34$ & 22 & 20 & 48 & 43 \\
\hline $35-44$ & 33 & 30 & 37 & 33 \\
\hline $45-69$ & 33 & 30 & 27 & 24 \\
\hline \multicolumn{5}{|l|}{ Marital status } \\
\hline Married & 74 & 84 & 76 & 67 \\
\hline Never married & 13 & 15 & 26 & 23 \\
\hline Separated & 1 & 1 & 3 & 4 \\
\hline Widowed & 0 & 0 & 7 & 6 \\
\hline \multicolumn{5}{|l|}{ Country of birth } \\
\hline Lebanon & 77 & 88 & 96 & 86 \\
\hline Australia & 10 & 11 & 16 & 14 \\
\hline Other & 1 & 1 & 0 & 0 \\
\hline \multicolumn{5}{|l|}{ Religion } \\
\hline Christian & 56 & 64 & 72 & 65 \\
\hline Muslim & 32 & 36 & 40 & 35 \\
\hline \multicolumn{5}{|l|}{ Educational level } \\
\hline University/tertiary & 23 & 26 & 25 & 22 \\
\hline $\begin{array}{l}\text { Trade qualification } \\
\text { and High School }\end{array}$ & 41 & 47 & 50 & 45 \\
\hline $\begin{array}{l}\text { Primary school } \\
\text { and no education }\end{array}$ & 24 & 27 & 37 & 33 \\
\hline \multicolumn{5}{|l|}{ Employment status } \\
\hline Employed full time & 46 & 52 & 32 & 28 \\
\hline Employed part time & 9 & 10 & 14 & 13 \\
\hline Unemployed & 12 & 14 & 0 & 0 \\
\hline Retired & 12 & 14 & 7 & 6 \\
\hline $\begin{array}{l}\text { Not in work force } \\
\text { (due to ill health) }\end{array}$ & 8 & 9 & 2 & 2 \\
\hline Home duties & 1 & 1 & 57 & 51 \\
\hline
\end{tabular}

Physical assessment data: A second body of data consisted of anthropometric measurements based on the NHF-RFPS 1989 (National Heart Foundation of Australia, 1990) methodology using standardized techniques and calibrated equipment. Each anthropometric assessment took approximately $20 \mathrm{~min}$ to complete. Subjects were weighed in light indoor clothing utilizing a digital scale to the nearest $0.1 \mathrm{Kg}$. Height was measured without shoes and recorded to the nearest $0.5 \mathrm{~cm}$ using a non-stretch measuring tape. The Body Mass Index (BMI), an indicator of body fatness, was calculated as body weight in kilograms divided by height in meters squared. A BMI of 27.3 or greater was used to classify the subjects as overweight. Waist was measured at the level of the umbilicus; hip girth was measured at the level of the gluteal protrusion to the nearest centimeter with the subject wearing light clothes and standing in an upright position. Hypertension was determined by two measurements of blood pressure taken 5 min apart. Measurements were taken from the right arm using a mercury sphygmomanometer while subjects were in a seated position. Subjects with a mean systolic pressure greater than, or equal to $140 \mathrm{mmHg}$ and a mean diastolic pressure greater than or equal to $90 \mathrm{mmHg}$ were classified as hypertensive (National Heart Foundation of Australia, 1990). Self-reported cholesterol levels were recorded; levels of $5.5 \mathrm{mmol} \mathrm{L}^{-1}$ were regarded as 
higher than desirable (National Heart Foundation of Australia, 1990). All measurements were taken by the same investigator.

Statistical analysis: Statistical analyses were conducted utilizing the Statistical Package for Social Sciences. Demographic variables included gender, religion, age, education, birthplace/date of arrival in Australia, socioeconomic status (determined by occupation and income). These were entered as potential predictor variables of the outcome measures.

Multiple risk factors were identified according to the 1989 NHF-RFPS classification criteria of diastolic blood pressure $\geq 95 \mathrm{~mm} \mathrm{Hg}$, blood cholesterol $\geq 5.5 \mathrm{mmol} \mathrm{L}^{-1}$ and regular cigarette smoking with subjects categorized as having 0-3 risk factors. Outcome variables were based on already established modifiable CVD risk factors of high blood pressure, physical inactivity or low physical activity, prevalence of cigarette smoking, overweight, obesity, high dietary intake of salt and fat and consumption of alcoholic beverages.

\section{RESULTS}

Hypertension: Forward stepwise regression identified age and gender as the strongest predictors of hypertension, $\chi^{2}(2,198)=19.24, p<0.001$. However, age was the strongest predictor of hypertension defined as having a systolic BP>160 $\mathrm{mmHg}$ and/or diastolic $\mathrm{BP}>95 \mathrm{~mm} \mathrm{Hg}$, or on prescribed tablets for hypertension.

Kruskal-Wallis analyses revealed that the oldest age group (45-69 years) had the highest levels of both systolic $\left(\chi^{2}(2,198)=35.16, \mathrm{p}<0.0001\right)$ and diastolic $\left(\chi^{2}(2,198)=31.35, \mathrm{p}<0.0001\right)$ blood pressure levels.

Mann-Whitney $U$ tests revealed that males had higher systolic $(\mathrm{z}=-3.37, \mathrm{p}<0.001)$ and diastolic blood pressure $(z=-3.47, p<0.001)$ levels than females.

Physical activity: Variations in the amount and duration of all types of physical activity categorized as (vigorous, less vigorous, walking and gardening/housework) undertaken per fortnight were found, as a function of religious affiliation, age, education and country of birth. Christians engaged in more vigorous physical activities than Muslims ( $\mathrm{z}=-2.32, \mathrm{p}<0.05)$ however, no significant differences were found between Christians and Muslims in the number of walking sessions for recreation or exercise, nor in the number of hours spent in gardening or performing housework activities. The youngest (2034 years) age group were most physically active, in vigorous activities $\left(\chi^{2}(2,198)=11.58, \mathrm{p}<0.05\right)$ and in less vigorous physical activities $\left(\chi^{2}(2,198)=7.83\right.$, $\mathrm{p}<0.05)$. Walking was also more prevalent in the young age group compared to the oldest (45-69 years) age group $\left(\chi^{2}(2,198)=6.15, \mathrm{p}<0.05\right)$ and the middle $(35-44$ years) aged group $(\mathrm{M}=3.27, \mathrm{SD}=7.16)$ walked the least.

Participants with tertiary/university level education were found to engage in the highest level of vigorous physical activity, when compared to the other two groups (no education or primary school education and secondary school education or trade $),\left(\chi^{2}(2,198)=10.80, p<0.01\right)$.

Forward multiple logistic regression revealed that the birth/arrival variable also predicted levels of physical activity, $\chi^{2}(2,198)=17.45, p<0.001$, indicating that people who have resided in Australia for more than 10 years had the lowest levels of physical activity (i.e., at levels below those believed to confer a positive 'training effect on the heart').

No significant differences were found in the amount of physical activity and/or exercise sessions undertaken fortnightly between males and females, or between the low ( $\$ 0$ to $\$ 41,000$ ) and medium to high ( $\$ 41,001$ and above) income earners.

Cigarette smoking: Smoking was prevalent in all age groups, at all educational levels and across all socioeconomic categories. Males $(\mathrm{M}=42.86$, $\mathrm{SD}=25.64)$ were found to smoke more than females $(\mathrm{M}=16.00, \mathrm{SD}=8.41),\left(\chi^{2}(1,199)=10.62, \mathrm{p}<0.01\right)$. However, no significant differences in smoking patterns were found between Christians and Muslims, low and high income earners, younger and older participants and between those who were highly educated or those with little or no formal education.

Body Mass Index (BMI): Overweight and obesity increased with age in both genders, with $41 \%$ of men and $38 \%$ of women overweight and $21 \%$ of men and $37 \%$ of women obese. There were no significant differences in BMI on the basis of gender, religion and income. However, there were significant BMI differences in relation to age, education and birth/arrival $(\mathrm{p}<0.0001)$. Subjects in the oldest age group $(\overline{\mathrm{x}}=29.51, \mathrm{~s}=4.46)$, with no formal education $(\bar{x}=29.98, s=4.58)$ and who had been in Australia longer than 10 years $(\bar{x}=28.76$, $\mathrm{s}=4.60)$ had the highest BMI values and could be classified as overweight. Using multiple forward logistic regression older age (45-69 years) was found to be the strongest predictor of an increased BMI $\left(\chi^{2}(2,198)=14.87, p<0.01\right)$. Older subjects were twice as likely to be overweight than the younger subjects $(\mathrm{OR}=2.262, \mathrm{p}<0.01)$. Significant differences were found between males and females in waist circumference $(\mathrm{z}=-5.69, \mathrm{p}<0.0001)$, with males having larger waist measurements. Older subjects, those with no formal education and those who had resided in Australia longer than 10 years had the largest waist and hip circumferences. 
Intl. J. Rec. Nursing 1 (1): 1-7, 2010

Table 2: Multiple forward logistic regression of association between demographic predictors and a major risk factor

\begin{tabular}{|c|c|c|c|c|c|c|}
\hline \multirow[b]{2}{*}{ Predictors } & \multicolumn{2}{|c|}{ Univariate estimates } & \multicolumn{4}{|c|}{ Multivariate model of best fit } \\
\hline & $\mathrm{B}$ & SE B & $\mathrm{B}$ & SE B & Odds ratio & $\mathrm{R}$ \\
\hline \multicolumn{7}{|l|}{$\begin{array}{l}\text { Age (years) } \\
\text { (year }\end{array}$} \\
\hline $20-34^{\mathrm{a}}$ & 0.082 & & & & & \\
\hline $35-44$ & -0.365 & 0.206 & 0.336 & 0.260 & 0.715 & -0.039 \\
\hline $45-69$ & $0.854 * * *$ & 0.217 & 0.570 & 0.290 & 1.780 & $0.116^{*}$ \\
\hline \multicolumn{7}{|l|}{ Religion } \\
\hline \multicolumn{7}{|l|}{ Christian $^{\mathrm{a}}$} \\
\hline Muslim & $0.046^{* *}$ & 0.148 & & & & \\
\hline \multicolumn{7}{|l|}{ Gender } \\
\hline \multicolumn{7}{|l|}{ Male $^{\mathrm{a}}$} \\
\hline Female & $-0.474 * *$ & 0.147 & 0.510 & 0.161 & 0.601 & $-0.171 * *$ \\
\hline \multicolumn{7}{|l|}{ Education } \\
\hline No formal or primary only ${ }^{a}$ & & & & & & $0.107 *$ \\
\hline Secondary or Trade & -0.246 & 0.197 & 0.244 & 0.280 & 0.783 & 0.000 \\
\hline University or Tertiary & $-0.497 *$ & 0.234 & 0.418 & 0.260 & 0.658 & -0.050 \\
\hline \multicolumn{7}{|l|}{ Income } \\
\hline \multicolumn{7}{|l|}{$<41,000$ per annum ${ }^{a}$} \\
\hline$>=41,000$ per annum & 0.139 & 0.143 & & & & \\
\hline \multicolumn{7}{|l|}{ Birth/arrival } \\
\hline \multicolumn{7}{|l|}{ Born in Australia ${ }^{a}$} \\
\hline Arrived in Australia $<10$ years & 0.052 & 0.247 & & & & \\
\hline Arrived in Australia $>10$ years & $0.636^{* *}$ & 0.218 & & & & \\
\hline
\end{tabular}

Diet: Chi square analyses identified significant differences in the frequency of eating fatty meat according to the birth/arrival, age and educational level categories. The most recent arrivals to Australia ( $<10$ years ago), those in the middle age group (3544 years) and those who had higher levels of education (tertiary/university) consumed less fatty meat $\left(\chi^{2}(2,198)=6.84, \mathrm{p}<0.05\right)$. No significant differences were among any of the remaining variables. Further, significant differences were not shown between any of the various groups in relation to salt intake, however, a trend of adding salt to cooked food was evident among males.

Alcohol consumption: Religion, gender and age were related to alcohol consumption Christians $(\mathrm{M}=0.59$, $\mathrm{SD}=0.51)$ consumed more alcoholic drinks than Muslims $(\mathrm{M}=0.06, \mathrm{SD}=0.23),(\mathrm{z}=-7.08, \mathrm{p}<0.0001)$ and men $(\mathrm{M}=0.52, \mathrm{SD}=0.52)$ consumed more alcoholic drinks than women $(\mathrm{M}=0.30, \mathrm{SD}=0.46)$ $(\mathrm{z}=-3.02, \mathrm{p}<0.01)$ and the middle aged group $(35-44$ years) were consuming the highest number of alcoholic drinks $(\mathrm{M}=0.53, \mathrm{SD}=0.53)$. No significant differences were evident in the consumption of alcoholic drinks according to income, education or birth/arrival categories.

Measurement of all predictor variables by major risk factors: A logistic regression analysis was conducted to identify the demographic factors that predicted the presence of a major risk factor. As shown in Table 2, the strongest predictor of CHD was gender, with men more likely to have at least one major risk factor $(\mathrm{p}<0.01)$. The second strongest predictor was age, with those in the oldest age group (45-69 years) being more likely to have a major risk factor $(\mathrm{p}<0.05)$. The next strongest predictor was education, with those with no formal education or primary school education being more likely than others to have a major risk factor $(\mathrm{p}<0.05)$.

When compared with the 1989 NHF-RFPS (National Heart Foundation of Australia, 1990) findings, the analysis indicated that a high proportion of the Australian-Lebanese had one or more of the three classical CVD risk factors (high blood pressure, high cholesterol and smoking). Thirteen percent of the men and $10 \%$ of women had two to three risk factors compared with $8 \%$ of the men and $5 \%$ of the women in the 1989 NHF-RFPS study. In addition, $45 \%$ of the men and $12 \%$ of the women in this study had one risk factor compared with $42 \%$ of the men and $8 \%$ of the women in the 1989 NHF-RFPS study. The 1989 NHFRFPS study findings indicated that the prevalence of CVD risk factors increased in subjects aged between 50-54 years of age. In this study, the prevalence of CVD increased with age but was evident at a younger age range (30-49 years) when compared with the general Australian population.

\section{DISCUSSION}

High blood pressure is an acknowledged major risk factor for CVD and stroke. This study found that $15 \%$ 
of the men and $7 \%$ of the women were hypertensive, although only $4 \%$ of the subjects reported that they had been told by their doctor that they had high blood pressure. The other 16 subjects who were found to have undetected hypertension were advised to consult their local doctor for further investigation and monitoring and, if necessary, treatment for their high blood pressure. This percentage is higher than that found in the NHF-RFPS study in which $11 \%$ of the men and 5\% of the women were identified as hypertensive (National Heart Foundation of Australia, 1990).

The multivariate analysis also showed that of all key variables age was the strongest predictor of hypertension, with the oldest age group having the highest systolic and diastolic blood pressure readings. Hypertension was prevalent particularly among the lower educated, especially in those who had resided in Australia for longer than 10 years. These findings are similar to a Melbourne study of Italian migrants (Ireland and Giles, 1996) which found that blood pressure increased with the longer duration of residence in Australia, especially in males aged 50-59 years. Several factors influence the development of hypertension, such as age, socio-economic status, education and gender (Winnicki et al., 2006). Other factors appear implicated in this study include inactive life style, overweight and smokers. All of these factors are known to increase high blood pressure and poses a greater risk factor for CVD events in the elderly (Winnicki et al., 2006).

Men in this study had higher blood pressure levels than women and reported a higher sodium intake. Surprisingly, no differences in blood pressure measurements were detected between the low and medium to high income earners, although many studies have identified a correlation between low socioeconomic status and hypertension (Winnicki et al., 2006; Taylor et al., 1999; Pearce and Smith, 2003).

Smoking in this study was prevalent in all age groups, at all educational levels and across all socioeconomic categories. This health practice alone is of considerable concern. Stress at home and at work, social isolation due to immigration and difficulties in finding appropriate employment in their new country, resulting in disillusionment and disappointment, were offered by subjects as reasons for smoking. Sixty seven smokers in this study, irrespective of age, education or religion, cited that smoking cigarettes had a "positive" effect on them. These effects included improved concentration, focus and mood and reduced anger, tension, depression and stress. These perceptions of the benefits of smoking acted as deterrents from attempting to "quit". The proportion of male smokers was much higher than female smokers: $44 \%$ compared with $25 \%$, respectively. Forty percent of smokers were in the oldest age group (45-69 years) and were mostly men. Older women had the lowest rate of smoking with the greatest proportion of female smokers being in the middle aged group (34-44 years) and in the youngest age group (20-34 years).

The smoking behavior in this sample is consistent with research conducted in the immigrant Lebanese community in Sydney which found that the prevalence of smoking among the Lebanese community exceeded that of the general New South Wales population (Rissel et al., 1999; Wen et al., 2002). Contrary to studies that have shown increased smoking among those from low socio-economic groups (Bennett and Magnus, 1994; Malmstadt et al., 2001; Minas et al., 1996) this research showed a high prevalence of smoking across income and education levels.

Being overweight and inactive were common CVD risk factors among the subjects of this study, predisposing them to diabetes and higher levels of cholesterol. The analysis indicated a higher prevalence of obesity in both Australian-Lebanese men and women compared with the 1989 NHF study (National Heart Foundation of Australia, 1990). In the latter study, 60\% of the men and $50 \%$ of the women were overweight or obese. In this study the figures were higher, with $71 \%$ of the men and $67 \%$ of women overweight or obese.

Implications: This study identified the high risk factors for CVD among a sample of Australian-Lebanese residing in Melbourne. These findings highlight the need to increase awareness and compliance with health promotion activities in relation to hypertension, obesity, lack of physical activity and smoking and the need for culturally appropriate health promotional programs. Such health promoting programs and campaigns should be geared towards the cessation of smoking, prevention and treatment of hypertension, weight reduction and engagement in physical activity. To be successful these campaigns must adopt a framework that is holistic in nature, thereby incorporating the physical, psychological and social aspects integral to good health.

\section{CONCLUSION}

This study provided the first formal investigation of CVD risk factors and predictors among adult Australian-Lebanese living permanently in Melbourne, Australia. Compared with Australian data the findings of this study indicate that the percentage of hypertension for both the Australian-Lebanese men and women was higher than that of the Australian-born men 
and women. However, the Australian-Lebanese had lower blood cholesterol levels, but markedly higher smoking levels especially amongst the men. Overweight, obesity and lack of exercise and physical activity in general, are contributing to an increased risk of cardiovascular events in this ethnic population.

These observations provide the basis for much needed interventional type studies and should lead to planning and implementing culturally appropriate health promotion and education programs for this specific community.

\section{REFERENCES}

Al-Roomi, K.A., A.J. Dobson, E. Hall, R.F. Heller and P. Magnus, 1989. Declining mortality from ischemic heart disease and cerebrovascular disease in Australia. Am. J. Epidemiol., 129: 503-510. http://aje.oxfordjournals.org/cgi/content/abstract/12 9/3/503

Australian Bureau of Statistics, 2006. 4364.0-national health survey: Summary of results, 2004-05. http://www.abs.gov.au/ausstats/abs@.nsf/Lookup/4 364.0Main+Features12004-05?OpenDocument

Australian Bureau of Statistics, 2006. Census of population and housing. http://www.abs.gov.au/WEBSITEDBS/D3310114. nsf/Home/census

Australian Bureau of Statistics, 2007. 3303.0- causes of death, Australia, 2005. http://www.abs.gov.au/AUSSTATS/abs@.nsf/Lookup/3 303.0Explanatory\%20Notes12005?OpenDocument

Australian Institute of Health and Welfare (AIHW), 2002. Australian health inequalities. http://www.aihw.gov.au/publications/aus/bulletin0 2/bulletin02.pdf

Australian Institute of Health and Welfare, 1992. Australia's health no. 3. http://www.aihw.gov.au/publications/index.cfm/title/24

Australian Institute of Health and Welfare, 2004 Heart, stroke and vascular disease, Australian facts 2004. http://www.aihw.gov.au/publications/index.cfm/titl e/10005

Bennett, S.A. and P. Magnus, 1994. Trends in cardiovascular risk factors in Australia. Results from the National Heart Foundation's risk factor prevalence study, 1980-1989 . Med. J. Aust., 161: 519-527.

http://www.ncbi.nlm.nih.gov/pubmed/7968750

Biddle, N., S. Kennedy and J.T. McDonald, 2007 Health assimilation patterns among Australian immigrants. Econ. Rec., 83 16-30. http://papers.ssrn.com/sol3/papers.cfm?abstract_id $=961895$
Brown, W.J., J. Alexander, B. McDonald and T. MillsEver, 1997. The health of Filipinas in the hunter region. Aust. N. Z. J. Public Health, 21: 214-216. http://www.ncbi.nlm.nih.gov/pubmed/9161081

Chaturvedi, N. and P.M. McKeigue, 1994. Methods for epidemiological surveys of ethnic minority groups. J. Epidemiol. Community Health, 48: 107-111. DOI: $10.1136 /$ jech.48.2.107

Department of Immigration and Citizenship, 2008. The people of Australia: Statistics from the 2006 census. http://www.immi.gov.au/media/publications/resear ch/_pdf/poa-2008.pdf

Department of Immigration and Multicultural and Indigenous Affairs, 2002. Medical examination for an Australian visa. http://www.immi.gov.au/allforms/pdf/26.pdf

Department of Immigration and Multicultural and Indigenous Affairs, 2003. Fact sheet 22. http://www.immi.gov.au/media/fact-sheets/

Ecob, R. and R. Williams, 1991. Sampling Asian minorities to assess health and welfare. J. Epidemiol. Community Health, 45: 93-101. DOI: 10.1136/jech.45.2.93

Hsu-Hage, B.H. and M.L. Walqvist, 1993. Cardiovascular risk in adult Melbourne Chinese. Aust. J. Public Health, 17: 306-13. http://www.ncbi.nlm.nih.gov/pubmed/8204710

Ireland, P.D. and G.G. Giles, 1996. Blood pressure in the Australian-and Italian-born: A Melbourne suburb revisited after 20 Years. Aust. N. Z. J. Public Health, 20: 143-148. DOI: 10.1111/j.17536405.1996.tb01808.x

Malmstadt, J.R., D.L. Nordstrom, D.C. Carty, A.L. Christansen and N.E. Chudy et al., 2001. Cigarette smoking in Wisconsin: The influence of race, ethnicity and socioeconomics. Wisconsin Med. J., 100: 29-33. http://www.ncbi.nlm.nih.gov/pubmed/11491027

Minas, I., T. Lambert, S. Kostov and G. Boranga, 1996. Mental Health Services for NESB Immigrants. Australian Government Publishing Service, Canberra, ISBN: 0644357827, pp: 164.

National Heart Foundation of Australia, 1982. Risk Factor Prevalence Study No.1, 1980. NHFA, Canberra.

National Heart Foundation of Australia, 1985. Risk Factor Prevalence Study No.2, 1983. NHFA., Canberra.

National Heart Foundation of Australia, 1990. Risk Factor Prevalence Study No. 3, 1989. NHFA., Canberra, ISBN: 10: 090947527X,pp: 141. 
Pearce, N. and G.D. Smith, 2003. Is social capital the key to inequlities in health? Am. J. Public Health, 93: 122-129. http://www.ajph.org/cgi/content/abstract/93/1/122

Plunkett, A. and S. Quine, 1996. Difficulties experienced by carers from non-English-speaking backgrounds in using health and other support services. Aust. N. Z. J. Public Health, 20: 27-32. DOI: 10.1111/j.1467-842X.1996.tb01332.x

Richardson, S., J. Healy, S. Stack, D. Ilsley, L. Lester and J. Horrocks, 2004. The changing settlement experience of new migrants. http://www.immi.gov.au/media/publications/multic ultural/lsia/labour-forcev2.pdf

Rissel, C. and C. Russell, 1993. Heart disease risk factors in the vietnamese community of South Western Sydney. Aust. J. Public Health, 17: 71-3. http://www.ncbi.nlm.nih.gov/pubmed/8357898

Rissel, C., J. Ward and L. Jorm, 1999. Estimates of smoking and related behavior in an immigrant Lebanese community: Does survey method matter? Aust. N. Z. J. Public Health, 23: 534-537. http://www.ncbi.nlm.nih.gov/pubmed/10575779

Small, R., J. Yelland, J. Lumley and P.L. Rice, 1999. Cross-cultural research: Trying to do it better. 1 . Issue in design. Aust. N. Z. J. Public Health, 23: $\quad 385-390 . \quad$ DOI: $\quad 10.1111 / \mathrm{j} .1467-$ 842X.1999.tb01280.x
Taylor, R., T. Chey, A. Bauman and I. Webster, 1999. Socio-economic, migrant and geographic differentials in coronary heart disease occurrence in New South Wales. Aust. N. Z. J. Public Health, 23: $\quad 20-6 . \quad$ DOI: $\quad 10.1111 / \mathrm{j} .1467-$ 842X.1999.tb01200.x

Wen, L.M., M. Hua and C. Rissel, 2002. Changes in smoke-free home status in an immigrant Lebanese community in Sydney Australia. Aust. N. Z. J. Public Health, 26: 78-79. DOI: 10.1111/j.1467842X.2002.tb00275.x

Wilson, A., J. Bekiaris, S. Gleeson, C. Papasavara, M. Wise and P. Howe, 1993. The good heart, good life survey: Self-reported cardiovascular disease risk factors, health knowledge and attitudes among Greek-Australians in Sydney. Aust. J. Public Health, 17: 215-221. http://www.ncbi.nlm.nih.gov/pubmed/8286493

Winnicki, M., V. Somers, F. Dorigatti, D. Longo and M. Santonastaso et al., 2006. Lifestyle, family history and progression of hypertension. J. Hypertens., $\quad 24$ : 1479-1487. DOI: 10.1097/01.hjh.0000239281.27938.d4 